\title{
The Application of Blended Teaching Model Based on Micro-Curriculum in Class Teaching of Engineering Mechanics
}

\author{
Ping Wei \\ School of Physics and Technology \\ University of Jinan \\ Jinan City, Shandong Province, P.R. China \\ ss_weip@ujn.edu.cn
}

\begin{abstract}
In view of the problems in the teaching of engineering mechanics in our university, such as the unique teaching methods, the difficulty in mobilizing the learning initiative and lack of ability to apply knowledge analysis to solve problems, the blended teaching model based on microcurriculum, problem-driven methods and flipping classrooms is applied to the teaching of engineering mechanics. The results show that the blended teaching model can effectively solve the above problems, improve students' interest in learning, and achieve better teaching results.
\end{abstract}

Keywords-Micro-curriculum; Blended teaching model; Problem-driven methods; Engineering mechanics

\section{INTRODUCTION}

The traditional teaching model has the advantages of high teaching efficiency and wide audience, but with the progress of the times, we now pay more attention to the individualized development of learners and the improvement of their overall quality. In the information-based environment, the curriculum reform in colleges and universities is also advancing at the pace of time. The teaching models, teaching contents and teaching methods are all seeking continuous innovation. The role of teachers is also being transformed from knowledge holders and trainers to organizers and directors of learning activities. For the teaching mode, it is changing to studentcentered. Blended teaching models based on micro-video, problem-driven, and flipping classrooms are gradually replacing traditional face-to-face teaching methods. The blended teaching model shifts from results-oriented evaluation to the combination of results and processes, and pays more attention to the learner's process evaluation. In the context of educational informatization, teachers need to provide rich learning resources and use a variety of teaching methods to organically combine problem-driven learning, web-based learning and participatory learning, so as to enrich college teaching models and stimulate students' interest in learning, and then improve student self-learning ability, thereby improving the quality of teaching.

Engineering mechanics is an important professional basic course for engineering majors. It is theoretically, systematically strong, logically rigorous, abstract, etc., and at the same time it is closely related to engineering technology and life [1]. In our university's New Energy Science and Engineering major, engineering mechanics is the first theoretical course that students can learn to contact directly with the actual engineering curriculum. It has an important enlightening role in cultivating students to establish engineering concepts and theoretically solve practical engineering problems. How to guide students to think deeply in the teaching of engineering mechanics, inspire students interest in learning and creative thinking, stimulate classroom atmosphere, and make the knowledge taught by "Engineering Mechanics" can be more vivid, easy to grasp and understand. It has become a difficult problem for teachers of engineering mechanics. Engineering mechanics has the nature of the curriculum, which has a close relationship between theoretical knowledge and engineering practice, a wide range of knowledge, many knowledge points, and flexible and diverse research methods. This determines that it is very suitable for blended teaching mode based on micro-curriculum [2].

\section{BLENDED TEACHING MODE BASED ON MICRO- CURRICULUM}

In April 2017, the New Media Alliance (NMC) of the United States introduced the latest issue of the Higher Education Version Horizon Report. This report listed blended learning designs in key trends in the short-term trends and pointed out that in the past few years, with the endless advent of MOOCs, open Internet courses, and excellent courses, more and more students have begun to use online learning extensively as one of the main ways to acquire knowledge. The so-called blended learning is a combination of "online learning" and "face-to-face learning", to meet the diverse learning needs of students. The biggest difference between the blended teaching mode and the traditional teaching mode is that the blended teaching mode has more emphasis on the choice of teaching methods and instructional design. It can better support the students' learning, better motivate the students' motivation for active learning, and promote students' motivation. Deep learning, such as the use of self-inquiry learning, discussion-discussion learning, and problem-driven 
learning methods, can truly implement the "student-centered" teaching philosophy in the specific teaching process.

We attempt to introduce the teaching mode of flipping classroom and problem-driven teaching based on microteaching into classroom teaching. This blended teaching mode starts from the dominant position of teachers and focuses on how to help students achieve optimal learning results. Teachers change from the transfer of knowledge to mentors, facilitators, and promoters in the process of student learning. In the entire teaching process, micro-assistance teaching and other network learning methods were introduced into classroom teaching to monitor students' real-time knowledge of the learned knowledge and provide reference for follow-up teaching process. Based on the micro-learning mode, the blended learning mode can organically combine the advantages of offline classroom learning and online e-learning to obtain optimal teaching effects. As an improvement and innovation in traditional classroom teaching, the blended teaching model can provide students with services that surpass the existing education and teaching system, and can also provide a broader space for the development of teachers' academic teaching.

\section{DESIGN OF BLENDED TEACHING MODEL FOR ENGINEERING MECHANICS}

We opened the engineering mechanics class through the "Micro Assistant Teaching" platform, which is mainly used by students of the university's New Energy Science and Engineering majors. In 2017, we teach some of the chapters of the engineering mechanics course with a blended teaching mode based on micro-teaching. On the basis of comprehensive consideration of teaching objectives, teaching resources and teaching conditions, the design of the blended teaching model was completed, including the following three parts:

\section{A. Design of Teaching Content}

The distinctive feature of micro-curriculum is that it embodies a "micro" feature and a relatively concentrated theme in teaching time and teaching content. It is a fragmented teaching. Engineering Mechanics is an important professional basic course for students of our university's New Energy Science and Engineering major. The nature of the curriculum and the teaching content closely related to its theoretical knowledge and engineering application, and this determines that it is more suitable for micro-curricular teaching.

Micro-curriculum is convenient for students to learn after the class. For difficult or difficult to understand knowledge, students can repeat learning until they are mastered. However, not all of the teaching content of this course is suitable for teaching in micro-curriculum. We use knowledge as a support to integrate the teaching videos, exercises, and discussion topics that are suitable for students' self-learning, and form a teaching content system with knowledge units. We comprehensively consider the teaching emphasis, difficulties and the professional syllabus of the course to integrate the following units suitable for teaching in micro-curriculums (Table 1) and record the video of the micro-curriculums of these knowledge points and corresponding key exercises. For the content that is not suitable for the use of micro teaching, the traditional classroom teaching mode is still used.

TABLE I. LIST OF MICRO-VIDEO

\begin{tabular}{|c|c|}
\hline Statics part & \\
\hline 1.The constraining force drawing & \\
2.Free-body diagram & \\
3.Theorem of translation force & \\
4.Reduction of planar force system & Angle of friction \\
5.Statics determinable and indeter -minable problems & \\
& \\
& \\
\hline
\end{tabular}

\section{B. Design of Teaching Process}

In the mixed teaching process, the teaching process is no longer confined to the traditional classroom teaching. Instead, it integrates the students' learning activities before, during, and after the lesson. Including the design of self-learning task lists before classes and the design of online learning resources, the planning and design of classroom teaching and seminar activities, and the design of research learning activities under the curriculum.

In the blended teaching process, the teaching process is no longer confined to the traditional classroom teaching. Instead, it is designed around students' pre-class, in-class and afterschool activities. This includes pre-class autonomy, the design
Mechanics of Materials

1. Method of section

2. Normal force diagram

3. Normal force

4. Shear

5.Effective bearing surface

6. Torsion

7. Torque

8. Torque diagram

9. Shearing stress

10.Bending

11.Bending moment

12.Bending moment diagram

13. Statically indeterminate problem

14.Pure bending

of learning task lists and the design of online learning resources, the planning and design of classroom teaching and seminar activities, and the design of research learning activities under the curriculum [3]. We took the students of the New Energy Science and Engineering major as the experimental subjects, and used the blended teaching model based on micro-teaching in some sections of the "Engineering Mechanics" course. The teaching process included the following three parts:

(1) Pre-class preparation: In order to improve students' ability of independent learning and smooth implementation of classroom teaching, the blended teaching model requires teachers to transmit teaching requirements and related micro- 
curricular video materials to students through the network before class so that students can learn independently. We teach students through the micro teaching assistant platform or the WeChat and QQ learning groups before the self-learning preparatory class, which includes the course requirements, teaching objectives, difficulties, basic knowledge points, micro video, and classroom teaching content. We require students to read these materials, watch videos, and complete self-study papers before class. In order to supervise students' learning, at the beginning of the class, we will check the student's preparatory work through the micro-teacher's answer function.

(2) Learning in class: In order to improve students' interest in learning and enthusiasm for learning, we comprehensively consider the characteristics of teaching content, teaching objectives and student characteristics. Different teaching contents adopt different teaching modes. For example, when studying the stability of the pressure bar, we adopt the BOPPPS teaching method based on the construction theory. The teaching method is divided into six sections: Bridge-in, Objective, Pre-assessment, Participatory Learning, Postassessment and Summary. In this teaching method, the emphasis is on student-centered and all-round participation in learning. When learning to improve the flexural strength of beams, students are required to review relevant basic knowledge points with the help of micro-classes before class. In the course of class teaching, problem-driven and class discussions are used to organically combine teaching methods. Teaching content is constantly used throughout the teaching process. Based on the knowledge accumulation of students and the background of practical engineering cases and common sense of life, this paper presents a series of questions that are in line with students' cognitive laws, and guide students to use the acquired knowledge to discover problems, analyze problems, and make use of engineering mechanics principles to solve the problem. This has greatly improved the students' learning enthusiasm and learning achievement.
(3) Consolidate and test after class: In order to test the learning effect of students, we use the answering and discussion functions in the micro-assistant learning platform to require learning. And we demand the student complete the corresponding exercises and the class discussion content, and write a learning report based on the learning content. Teachers can learn students' learning status in real-time through micro teaching assistants, including the learning status of teaching micro-videos, answering questions in the classroom, participating in discussions, and the completion of after-class tests, so that they can give students feedback in time and plan their follow-up accordingly teaching tasks.

\section{CONCLUSION}

The blended teaching mode has realized the combination of micro-teaching and face-to-face teaching. Not only can it achieve deep integration of online teaching and offline classroom teaching, it extends traditional classroom teaching. In the process of teaching practice, students' autonomous learning ability and ability to independently solve problems have been significantly improved, and teachers' values have been fully realized. The teaching effect of engineering mechanics is also improved.

\section{ACKNOWLEDGMENT}

This research has been supported by the Foundation of Teaching and Research of University of Jinan (No. J1708).

\section{REFERENCES}

[1] Chu Xihua, Xu Yuanjiel, "A tentative discussion on the teaching in engineering mechanics course based on taxonomt of educationa objectives theory," Mechanics in Engineering vol. 37, 2015, pp.117-119.

[2] Xia Dongsheng, Yu Yan, Zhu Gongzhi, Jin Rong, "Exploration on Micro-lecture Design and Making for Engineering Mechanics," China Modern Educational Equipment, vol. 233, 2016, pp. 73-76.

[3] Li Fengqing, "The Theoretical Basis and Instructional Design of Blending Teaching," Modern Educational Technology, vol.26, No.9 2016, pp. 18-24. 